\title{
Association between overweight and characteristics of young adult students: support for nursing care ${ }^{1}$
}

\author{
Jênifa Cavalcante dos Santos Santiago² \\ Thereza Maria Magalhães Moreira ${ }^{3}$ \\ Raquel Sampaio Florêncio ${ }^{4}$
}

Objective: to verify associations between overweight and the characteristics of young adult students to support nursing care. Method: case-control study conducted with young adults from public schools. The sample was composed of 441 participants (147 cases and 294 controls, with and without excess weight, respectively). Sociodemographic and clinical characteristics were collected together with exposure factors and anthropometrics. Multiple logistic regression was used. The study received Institutional Review Board approval. Results: statistically significant association with overweight: non-Caucasian, having a partner; weight gain during adolescence, mother's excess weight, the use of obesogenic medication, augmented diastolic blood pressure, of abdominal circumference and waist/hip ratio. In addition to these, schooling and weight gain during childhood were also included in the multivariate analysis. After adjustment, the final model included: having a partner, weight gain during adolescence, augmented diastolic blood pressure and abdominal circumference. Conclusion: the analysis of predictor variables for excess weight among young adult students supports nurses in planning and developing educational practices aimed to prevent this clinical condition, which is a risk factor for other chronic comorbidities, such as cardiovascular diseases.

Descriptors: Nursing; Overweight; Obesity; Young Adult.

\footnotetext{
1 Paper extracted from master's thesis "Analysis of obesity in adults young school: subsidy for health education by nurse", presented to Universidade Estadual do Ceará, Fortaleza, CE, Brazil.

2 Doctoral student, Universidade Estadual do Ceará, Fortaleza, CE, Brazil. Professor, Universidade Estadual do Ceará, Fortaleza, CE, Brazil. Scholarship holder from Coordenação de Aperfeiçoamento de Pessoal de Nível Superior (CAPES), Brazil.

3 Post-doctoral fellow, Faculdade de Saúde Pública, Universidade de São Paulo, São Paulo, SP, Brazil. Professor, Universidade Estadual do Ceará, Fortaleza, CE, Brazil.

4 Master's student, Universidade Estadual do Ceará, Fortaleza, CE, Brazil. Scholarship holder from Coordenação de Aperfeiçoamento de Pessoal de Nível Superior (CAPES), Brazil.
}

Corresponding Author:

Jênifa Cavalcante dos Santos Santiago

Universidade Estadual do Ceará

Av. Dr. Silas Munguba, 1700

Campus do Itaperi

CEP: 60714-903, Fortaleza, CE, Brasil

E-mail: jenifacs@yahoo.com.br
Copyright (c) 2015 Revista Latino-Americana de Enfermagem This is an Open Access article distributed under the terms of the Creative Commons Attribution Non-Commercial License (CC BY-NC).

This license lets others distribute, remix, tweak, and build upon your work non-commercially, and although their new works must also acknowledge you and be non-commercial, they don't have to license their derivative works on the same terms. 


\section{Introduction}

Overweight and obesity are conditions on the rise among young adults and nurses need to work on the prevention of these conditions to improve the quality of life of this population.

One report conducted by the World Health Organization (WHO) states that obesity is the cause of death of 2.8 million people a year and $12 \%$ of the current world population is considered obese. A total of $26 \%$ of the adults on the American continent is obese; the region in which the condition is the most incident in the world. The WHO's department of statistics reports that obesity doubled between 1980 and 2008 around the world ${ }^{(1)}$.

In Brazil, excess weight is considered an important nutritional disorder. Accumulation of body fat often begins during childhood and adolescence and persists into adulthood, possibly leading to physiopathological effects in adulthood ${ }^{(2)}$.

The determination of overweight and obesity results from a set of factors that constitute the lifestyle of modern populations, consuming increasingly processed, energy-dense foods rich in sugar, fat and sodium, with calories above individual needs. This imbalance stems partly from changes in dietary patterns, combined with reduced exercise in both work and leisure activities ${ }^{(3)}$.

It is important to stress multiple and heterogeneous determinants (biological, historic, ecological, social, cultural and political factors) of overweight. Environmental and social causes are in the sphere in which individuals have little or no ability to interfere ${ }^{(4)}$.

It is apparent, in this context, that obesity is not a problem of developed countries only; it also affects a portion of less favored populations. Therefore, government authorities as well as nurses and other health care workers need to mobilize to establish priorities and strategies to promote health and control health conditions.

It is worth noting that the emphasis concerning this public health problem in the school context has been directed to specific groups: children and adolescents ${ }^{(5-7)}$. The young adult population (20 to 24 years old) still attending school, however, has not been included in research, which justifies this study.

The question guiding this study was: Is there any association between weight excess and the characteristics of young adult students? What factors associated with overweight are susceptible to nursing interventions?
Therefore, studies analyzing intervenient factors are needed to support educational actions nurses have to develop when providing care to overweight young adult students. The objective of this study was to verify the association between overweight and characteristics of young adult students to support nursing care.

This study's objective was to verify the association between overweight and characteristics of young adult students to support nursing care.

\section{Method}

This observational case-control study of a quantitative nature was conducted with young adult students from public schools, including both overweight and obese individuals (case group) and individuals not classified as obese or overweight (control groups).

The study setting was the city of Maracanaú, located in the Metropolitan region of Fortaleza, Ceará, Brazil, with a population of 200,797 inhabitants ${ }^{(8)}$. It is an urban region with a large number of industries and has the second highest budget revenue of Ceará.

The study's dependent variable was overweight/ obesity. The independent variables were organized in hierarchical blocks to enable the multivariate analysis. The first block was composed of sociodemographic variables and the second block was composed of clinical and exposure variables.

We calculated samples of case-control studies and obtained a minimum of 172 for the control group and 86 people for the case group, considering a proportion of $2: 1$, which ensures statistic and operational efficiency and control selection bias. Because this paper is derived from a larger funded project, we decided to include in the sample the total of cases collected ( $n=147$ students with body mass index $(B M I) \geq 25 \mathrm{~kg} / \mathrm{m}^{2}$ ) and two controls for each case $\left(n=294\right.$ people with BMI $\geq 18.5 \mathrm{Kg} / \mathrm{m}^{2}$ and $<25 \mathrm{~kg} / \mathrm{m}^{2}$ ), totaling 441 people.

All the participants were recruited in public schools in the city and met the inclusion criteria (being regularly enrolled, aged between 20 and 24 years old with BMI equal to or higher than $18.5 \mathrm{Kg} / \mathrm{m}^{2}$ ). Age and occupation were considered to match the case and control groups.

Data were collected from November 2011 to April 2012. One questionnaire addressing sociodemographic and clinical data together with anthropometric measures was applied. The variables: race, weight gain in childhood and in adolescence, paternal and maternal weight gain smoking and alcohol consumption were self-reported. The daily ingestion of sugary and fatty foods and poor 
ingestion of fruits and greens was considered to be an unbalanced diet. Less than 150 minutes of moderate activity per week was considered sedentariness in accordance to the International Physical Activity Questionnaire (IPAQ).

The anthropometric measures were taken in a standardized manner. The abdominal circumference was measured with an inextensible tape measure putting clothing away, locating the midpoint between the iliac crest and the last rib. Measures below $88 \mathrm{~cm}$ for women and $102 \mathrm{~cm}$ for men were considered normal. The hip circumference was verified at the level of the anterior trochanter border and its relationship with the waist was also verified. The waist/hip ratio was considered normal among women with waist/hip $=0.85$ and waist/ hip $=0.95$ was considered normal for men ${ }^{(9)}$. Weight and height were determined using an anthropometric scale for adult individuals. The participants were standing with their arms close to the body, wearing the least weight in clothing possible without shoes.

The body mass index was computed only to assign the study's participants to either case or control group but the variable was not considered in the statistical analysis since its frequency was pre-established.

A database was created in the Statistical Package for the Social Sciences (SPSS) version 20.0, where variables were intersected and data were statistically analyzed.

Descriptive statistics (mean and standard deviation) were used and associations among risk factors were verified through the non-parametric Chisquare test between the explanatory variables and outcome, with level of significance at $5 \%$, to perform the multivariate analysis. Afterwards, we verified the strength of the association among variables by using odds ratio and respective confidence intervals. Then, logistic regression analysis was performed to adjust for potential confounding effects considering $p<0.20$. The factors were hierarchically selected into blocs for the final model, considering $p<0.05$.

This study followed the ethical and legal precepts concerning research conducted with human subjects and received approved from the Institutional Review Board at the State University of Ceará (UECE), No. 11516679-3.

\section{Results}

The description and analysis involved the predictor variables (sociodemographic, clinical-epidemiological, and exposure aspects) and outcome variables (overweight or obesity), as presented in Table 1.

As shown in Table 1, most participants from both groups (case and control) were aged between 20 and 22 years, were Non-Caucasians, had no partner, had a family income of up to two times the minimum wage, did not live in slums, were attending $1^{\text {st }}$ or $2^{\text {nd }}$ year of high school, and parents had attended up to eight years of school. Only the sex variable showed difference between groups: women were predominant in the case group while men predominated in the control group.

Table 2 presents the clinical characteristics of the young adult students verified by taking measures using appropriate equipment and technique.

Predominance of the following variables was verified in both cases and controls: normal weight during childhood and adolescence, absence of weight excess among parents, normal systolic and diastolic blood pressure, and normal abdominal circumference and waist/hip ratio, no smoking, no alcohol consumption, no unbalanced diet, no sedentariness or obesogenic medications.

Statistically significant associations were found in the bivariate analysis between the following sociodemographic characteristics and overweight/ obesity $(p<0.05)$ : Being non-Caucasian and having a partner. For the following clinical and exposure characteristics, statistically significant associations were found for overweight and obesity $(p<0.05)$ : excess weight during adolescence; mother's history of excess weight; altered diastolic blood pressure; augmented abdominal circumference; augmented waist/hip ratio; and the use of obesogenic medication. Variables had to present association $\mathrm{p}<0.20$ to be included in the adjustment of the logistic regression model. Hence, being a senior student (grade 12) and excess weight during childhood were also selected for the multivariate analysis.

After identifying variables $p<0.20$ we proceeded to the multivariate analysis with the adjustment stage (Table 3).

When analyzing the effect of sociodemographic characteristics (block 1) on overweight/obesity, being non-Caucasian and having a partner remained significant $(p<0.05)$. The analysis concerning the effect of clinical characteristics and exposure (block 2) on overweight/ obesity showed that excess weight during adolescence, hypertension (based on diastolic blood pressure) and augmented abdominal circumference were significant $(p<0.05)$. Waist/hip ratio was not significant due to 
the strong correlation with the variable abdominal circumference (coefficient $r$ de Pearson $=0.502$, $p<0.001$ ). This is expected since abdominal circumference is used to calculate the waist/hip ratio.

Table 4 presents the variables that remained in the final model. Multiple logistic regression was performed with the variables from blocks 1 and 2, which were $p<0.05$ in the adjustment stage. In this final stage, race did not remain significant and was withdrawn from the model, remaining only the marital status "have a partner", excess weight during adolescence, hypertension (diastolic arterial blood pressure) and augmented abdominal circumference.
Analysis of the residuals was performed to identify points in which the model had low adherence and points that improperly influenced the model. Standardized Cook's statistics were performed, considering DFBeta below 1 for all the variables and standardized residuals below 3, according to recommended parameters.

Table 4 shows that the final regression model was composed of constant, marital status, weight during adolescence, diastolic blood pressure, and abdominal circumference. All presented a positive relationship with the outcome, evidenced by $\operatorname{Exp} b>1$. Hence, the variables composing the final model are potential early indicators that lead to excess weight.

Table 1 - Bivariate analysis of sociodemographic characteristics associated with overweight/obesity in young adult students. Maracanaú, CE, Brazil, 2012

\begin{tabular}{|c|c|c|c|c|c|c|c|c|}
\hline \multirow[t]{2}{*}{ Variable } & \multicolumn{3}{|c|}{$\begin{array}{c}\text { Cases } \\
\mathrm{BMI} \geq 25 \mathrm{~kg} / \mathrm{m}^{2}\end{array}$} & \multicolumn{3}{|c|}{$\begin{array}{c}\text { Controls } \\
25 \mathrm{~kg} / \mathrm{m}^{2}>\mathrm{BMI} \geq 18.5 \mathrm{Kg} / \mathrm{m}^{2}\end{array}$} & \multirow[t]{2}{*}{$\mathbf{p}^{*}$} & \multirow[t]{2}{*}{ Raw odds ratio (Cl 95\%) } \\
\hline & $f$ & $\%$ & Mean (SD) & $f$ & $\%$ & Mean (SD) & & \\
\hline \multicolumn{9}{|l|}{ Age } \\
\hline 20 to 22 years old & 114 & $77.60 \%$ & $21.9( \pm 1.42)$ & 253 & $86.10 \%$ & $20.93( \pm 1.19)$ & & 1 \\
\hline 23 to 24 years old & 33 & $22.40 \%$ & & 41 & $13.90 \%$ & & 0.325 & $1.79(1.07-2.97)$ \\
\hline \multicolumn{9}{|l|}{ Sex } \\
\hline Male & 71 & $48.30 \%$ & & 150 & $51.00 \%$ & & & 1 \\
\hline Female & 76 & $51.70 \%$ & & 144 & $49.00 \%$ & & 0.590 & $1.12(0.75-1.66)$ \\
\hline \multicolumn{9}{|l|}{ Self-reported race } \\
\hline Caucasian & 57 & $38.80 \%$ & & 79 & $26.90 \%$ & & & 1 \\
\hline Non-Caucasian & 90 & $61.20 \%$ & & 215 & $73.10 \%$ & & 0.011 & $0.58(0.38-0.88)$ \\
\hline \multicolumn{9}{|l|}{ Marital status } \\
\hline Partner & 50 & $34.00 \%$ & & 45 & $15.30 \%$ & & & 1 \\
\hline No partner & 97 & $66.00 \%$ & & 249 & $84.70 \%$ & & 0.000 & $2.85(1.79-4.55)$ \\
\hline \multicolumn{9}{|l|}{ Family Income } \\
\hline Up to 2 times $\mathrm{MW} \dagger$ & 117 & $79.60 \%$ & & 237 & $80.60 \%$ & & & 1 \\
\hline More than 2 times MW & 30 & $20.40 \%$ & & 57 & $19.40 \%$ & & 0.800 & $1.07(0.65-1.75)$ \\
\hline \multicolumn{9}{|l|}{ Live in Slums } \\
\hline Yes & 11 & $7.50 \%$ & & 19 & $6.50 \%$ & & & 1 \\
\hline No & 136 & $92.50 \%$ & & 275 & $93.50 \%$ & & 0.689 & $1.17(0.54-2.53)$ \\
\hline \multicolumn{9}{|l|}{ Grade } \\
\hline High School & 90 & $62.10 \%$ & & 158 & $55.60 \%$ & & & 1 \\
\hline Senior year (Grade 12) & 55 & $37.90 \%$ & & 126 & $44.40 \%$ & & 0.202 & $0.77(0.51-1.15)$ \\
\hline \multicolumn{9}{|l|}{ Father's schooling } \\
\hline Up to 8 years & 75 & $51.00 \%$ & & 147 & $50.00 \%$ & & 0.950 & 1 \\
\hline More than 8 years & 39 & $26.50 \%$ & & 77 & $26.20 \%$ & & 0.804 & $1.07(0.61-1.89)$ \\
\hline Do not know & 33 & $22.40 \%$ & & 70 & $23.80 \%$ & & 0.976 & $0.99(0.62-1.60)$ \\
\hline \multicolumn{9}{|l|}{ Mother's schooling } \\
\hline Up to 8 years & 82 & $55.80 \%$ & & 155 & $52.70 \%$ & & 0.817 & 1 \\
\hline More than 8 years & 36 & $24.50 \%$ & & 75 & $25.50 \%$ & & 0.849 & $1.06(0.59-1.92)$ \\
\hline Do not know & 29 & $19.70 \%$ & & 64 & $21.80 \%$ & & 0.691 & $0.91(0.56-1.47)$ \\
\hline
\end{tabular}

*Chi-square statistical significance; + Minimum wage (MW) current in Brazil in 2012: R\$622 Reais 
Table 2 - Bivariate analysis of clinical and exposure characteristics associated with overweight/obesity in young adult students. Maracanaú, CE, Brazil, 2012

\begin{tabular}{|c|c|c|c|c|c|c|c|c|}
\hline \multirow{2}{*}{ Variable } & \multicolumn{3}{|c|}{$\begin{array}{c}\text { Cases } \\
\mathrm{BMI} \geq 25 \mathrm{~kg} / \mathrm{m}^{2}\end{array}$} & \multicolumn{3}{|c|}{$\begin{array}{c}\text { Controls } \\
25 \mathrm{~kg} / \mathrm{m}^{2}>\mathrm{BMI} \geq 18.5 \mathrm{Kg} / \mathrm{m}^{2}\end{array}$} & \multirow[t]{2}{*}{$\mathbf{p}^{*}$} & \multirow{2}{*}{ Raw Odds Ratio ( $\mathrm{Cl} 95 \%)$} \\
\hline & $f$ & $\%$ & Mean (SD) & $f$ & $\%$ & Mean (SD) & & \\
\hline \multicolumn{9}{|c|}{ Weight during childhood } \\
\hline No overweight & 123 & $83.70 \%$ & & 265 & $90.10 \%$ & & 0.051 & 1 \\
\hline Overweight & 24 & $16.30 \%$ & & 29 & $9.90 \%$ & & & $1.78(1.01-3.19)$ \\
\hline \multicolumn{9}{|c|}{ Weight during childhood } \\
\hline No overweight & 108 & $73.50 \%$ & & 281 & $95.60 \%$ & & 0.000 & 1 \\
\hline Overweight & 39 & $26.50 \%$ & & 13 & $4.40 \%$ & & & $7.81(4.01-15.19)$ \\
\hline \multicolumn{9}{|c|}{ Father's weight gain } \\
\hline No overweight & 120 & $81.60 \%$ & & 240 & $81.60 \%$ & & 1.000 & 1 \\
\hline Overweight & 27 & $18.40 \%$ & & 54 & $18.40 \%$ & & & $1.00(0.60-1.67)$ \\
\hline \multicolumn{9}{|c|}{ Father's weight gain } \\
\hline No overweight & 97 & $66.00 \%$ & & 228 & $77.60 \%$ & & 0.010 & 1 \\
\hline Overweight & 50 & $34.00 \%$ & & 66 & $22.40 \%$ & & & $1.78(1.15-2.76)$ \\
\hline \multicolumn{9}{|c|}{ Systolic blood pressure } \\
\hline Normotensive & 142 & $96.60 \%$ & $117.01( \pm 13.46)$ & 285 & $96.90 \%$ & $112.05( \pm 11.99)$ & 0.848 & 1 \\
\hline Hypertension & 5 & $3.40 \%$ & & 9 & $3.10 \%$ & & & $1.12(0.37-3.39)$ \\
\hline \multicolumn{9}{|c|}{ Diastolic blood pressure } \\
\hline Normotensive & 127 & $86.40 \%$ & $75.67( \pm 14.43)$ & 288 & $98.00 \%$ & $68.76( \pm 10.37)$ & 0.000 & 1 \\
\hline Hypertensive & 20 & $13.60 \%$ & & 6 & $2.00 \%$ & & & $7.56(2.97-19.27)$ \\
\hline \multicolumn{9}{|l|}{$\begin{array}{l}\text { Abdominal } \\
\text { circumference }\end{array}$} \\
\hline Normal & 99 & $67.30 \%$ & M:91.85 (₫9.86) & 291 & $99.00 \%$ & M:76.51 ( \pm 5.50$)$ & 0.000 & 1 \\
\hline Altered $^{\dagger}$ & 48 & $32.70 \%$ & $F: 90.27( \pm 10.11)$ & 3 & $1.00 \%$ & $F: 74.74( \pm 6.66)$ & & $47.03(14.33-154.36)$ \\
\hline \multicolumn{9}{|l|}{ Waist/hip ratio } \\
\hline Normal & 107 & $72.80 \%$ & M:0.86 $( \pm 0.62)$ & 260 & $88.40 \%$ & M:0.82 ( $( \pm 0.08)$ & 0.000 & 1 \\
\hline Altered $\ddagger$ & 40 & $27.20 \%$ & $\mathrm{~F}: 0.85( \pm 0.74)$ & 34 & $11.60 \%$ & $\mathrm{~F}: 0.80( \pm 0.09)$ & & $2.86(1.72-4.76)$ \\
\hline \multicolumn{9}{|l|}{ Smoking } \\
\hline No & 129 & $87.80 \%$ & & 250 & $85.00 \%$ & & 0.439 & 1 \\
\hline Yes & 18 & $12.20 \%$ & & 44 & $15.00 \%$ & & & $0.79(0.44-1.43)$ \\
\hline \multicolumn{9}{|l|}{ Alcohol } \\
\hline No & 41 & $29.90 \%$ & & 85 & $32.10 \%$ & & 0.660 & 1 \\
\hline Yes & 96 & $70.10 \%$ & & 180 & $67.90 \%$ & & & $1.11(0.71-1.73)$ \\
\hline \multicolumn{9}{|c|}{ Unbalanced diet } \\
\hline No & 71 & $48.30 \%$ & & 126 & $42.90 \%$ & & 0.279 & 1 \\
\hline Yes & 76 & $51.70 \%$ & & 168 & $57.10 \%$ & & & $0.80(0.54-1.20)$ \\
\hline \multicolumn{9}{|l|}{ Sedentariness } \\
\hline No & 28 & $19.00 \%$ & & 53 & $18.00 \%$ & & 0.794 & 1 \\
\hline Yes & 119 & $81.00 \%$ & & 241 & $82.00 \%$ & & & $0.93(0.56-1.55)$ \\
\hline \multicolumn{9}{|c|}{ Obesogenic medication } \\
\hline No & 104 & $70.70 \%$ & & 233 & $79.30 \%$ & & 0.048 & 1 \\
\hline Yes & 43 & $29.30 \%$ & & 61 & $20.70 \%$ & & & $1.58(1.01-2.49)$ \\
\hline
\end{tabular}

*Chi-square test's level of significance $+>88 \mathrm{~cm}$ for women and $>102$ for men; $\neq>0.85$ for women and $>0.95$ for men. 
Table 3 - Multivariate analysis of sociodemographic characteristics (block 1 ), clinical characteristics and other exposure factors (block 2), associated with overweight/obesity in young adult students. Maracanaú, CE, Brazil. 2012

\begin{tabular}{|c|c|c|c|c|}
\hline Variables & $\mathrm{p}$ & Raw odds ratio & $\mathbf{p}^{*}$ & Adjusted odds ratio $(95 \% \mathrm{Cl})$ \\
\hline \multicolumn{5}{|l|}{ Block 1} \\
\hline \multicolumn{5}{|l|}{ Self-reported race } \\
\hline Caucasian & & 1.00 & & 1.00 \\
\hline Non-Caucasian & 0.0110 & $0.58(0.38-0.88)$ & 0.030 & $0.62(0.40-0.96)$ \\
\hline \multicolumn{5}{|l|}{ Marital status } \\
\hline No partner & & 1.00 & & 1.00 \\
\hline Partner & 0.000 & $2.85(1.79-4.55)$ & 0.000 & $2.95(1.82-4.78)$ \\
\hline \multicolumn{5}{|l|}{ Schooling } \\
\hline High School & & 1.00 & & 1.00 \\
\hline Senior year (Grade 12) & 0.202 & $0.77(0.51-1.15)$ & 0.549 & $0.88(0.57-1.34)$ \\
\hline \multicolumn{5}{|l|}{ Block 2} \\
\hline \multicolumn{5}{|c|}{ Weight during childhood } \\
\hline No overweight & & 1.00 & & 1.00 \\
\hline Overweight & 0.051 & $1.78(1.01-3.19)$ & 0.823 & $1.09(0.52-2.26)$ \\
\hline \multicolumn{5}{|c|}{ Weight during adolescence } \\
\hline No overweight & & 1.00 & & 1.00 \\
\hline Overweight & 0.000 & $7.81(4.01-15.19)$ & 0.000 & $6.46(2.98-13.99)$ \\
\hline \multicolumn{5}{|l|}{ Mother's weight gain } \\
\hline No overweight & & 1.00 & & 1.00 \\
\hline Overweight & 0.010 & $1.78(1.15-2.76)$ & 0.374 & $1.28(0.74-2.19)$ \\
\hline \multicolumn{5}{|c|}{ Diastolic blood pressure } \\
\hline Normotensive & & 1.00 & & 1.00 \\
\hline Hypertensive & 0.848 & $1.12(0.37-3.39)$ & 0.001 & $6.04(2.10-17.38)$ \\
\hline \multicolumn{5}{|c|}{ Abdominal circumference } \\
\hline Normal & & 1.00 & & 1.00 \\
\hline Altered & 0.000 & $47.03(14.33-154.36)$ & 0.000 & $54.47(13.55-219.04)$ \\
\hline \multicolumn{5}{|l|}{ Waist/hip ratio } \\
\hline Normal & & 1.00 & & 1.00 \\
\hline Altered & 0.000 & $2.86(1.72-4.76)$ & 0.274 & $0.62(0.26-1.46)$ \\
\hline \multicolumn{5}{|l|}{ Unbalanced diet } \\
\hline No & & 1.00 & & 1.00 \\
\hline Yes & 0.279 & $0.80(0.54-1.20)$ & 0.085 & $0.66(0.41-1.06)$ \\
\hline \multicolumn{5}{|l|}{ Obesogenic medication } \\
\hline No & & 1.00 & & 1.00 \\
\hline Yes & 0.048 & $1.58(1.01-2.49)$ & 0.429 & $1.26(0.71-2.22)$ \\
\hline
\end{tabular}

$*_{\mathrm{p}}$ : Chi-square level of significance

Table 4 - Final model of the logistic regression. Maracanaú, CE, Brazil, 2012

\begin{tabular}{|c|c|c|c|c|}
\hline & \multirow{2}{*}{ B (standard error) } & \multicolumn{3}{|c|}{ Confidence interval of $95 \%$ for Exp b } \\
\hline & & Inferior & Exp b & Superior \\
\hline \multicolumn{5}{|l|}{ Included } \\
\hline Constant & $-6.59(0.92)^{*}$ & & & \\
\hline Marital status & $0.89(0.29) \dagger$ & 1.40 & 2.44 & 4.27 \\
\hline Weight during adolescence & $1.84(0.38)^{*}$ & 2.98 & 6.30 & 13.31 \\
\hline Diastolic blood pressure & $1.96(0.54)^{*}$ & 2.49 & 7.11 & 20.28 \\
\hline Abdominal circumference & $3.48(0.62)$ * & 9.59 & 32.42 & 109.54 \\
\hline
\end{tabular}

Note: $\mathrm{R}^{2}=0.20$ (Hosmer and Lemeshow), 0.28 (Cox \& Snell), 0.39 (Nagelkerke). $X^{2}$ model $=143.64, p<0.001 . * p<0.001,+p<0.01$. 


\section{Discussion}

Having a partner, considered in this study as being in a stable union or married, was statistically associated with overweight/obesity in both the bivariate and multivariate analysis, and remained in the final model. One study ${ }^{(10)}$ conducted with the employees of a federal university verified that marital status was strongly associated with overweight and obesity, and prevalence was lower among single individuals, 41.8 and $1.8 \%$, respectively. Another study ${ }^{(1)}$ found significant risk estimates $(p<0.001)$ among men with a partner $(P R=1.88)$. Another study ${ }^{(12)}$ conducted with adults in Maranhão verified that not having a partner was associated with lower prevalence of abdominal obesity ( $P R=0.28)$.

We suggest that marriage may influence weight gain due to changes in social behavior, which lead to increased caloric ingestion, due to foods rich in fat and sugar and decreased energetic expenditure, as a consequence of neglecting more rigorous physical activities and increased visits to restaurants and coffee shops as leisure. Additionally, couples tend to concern less with their self-image.

Current literature indicates that young adults are at risk of becoming obese or gaining excess weight when transitioning from childhood into adolescence or from adolescence into adulthood. The most critical periods of life for the development of obesity are early childhood, during the strong fluctuation in the trajectory of body fat that occurs between five and seven years old, and adolescence. From six years of age onwards, approximately one in every two obese children become an obese adult while only one in ten non-obese children become obese in adulthood(13-14).

With regard to weight gain during adolescence, it was statistically significant in the bivariate analysis and remained in the final model when tested in the multivariate analysis, showing that young adults with a history of excess weight during adolescence are 6.3 times more likely to develop overweight/obesity in adulthood.

Some studies report that obesity during childhood and adolescence is a concern because, if not controlled, the prognosis is increased morbidity and reduced life expectancy ${ }^{(15-16)}$, as it is associated with dyslipidemia, hypertension, glucose intolerance, psychosocial difficulties and increased risk of persistent obesity during adulthood(6).

The literature usually addresses hypertension as a consequence of weight gain(7,17). In this study, an association between hypertension as predictor variable and overweight/obesity as outcome could be identified. Both systolic and diastolic blood pressures were verified to check for hypertension and only the latter showed statistic significance as outcome, both in the bivariate and multivariate analysis, so that diastolic blood pressure remained in the final model. Hence, this study shows that hypertensive individuals are seven times more likely to develop overweight/obesity.

One cross-sectional study(18) applied multiple logistic regression to verify the variables associated with overweight and obesity and the adjusted analysis showed that hypertension was one of the variables that were statistically associated $(p<0.05)$ with overweight. Hypertensive individuals were 3.3 times more likely to develop overweight than normotensive ones. The analysis of obesity showed that hypertensive individuals were five times more likely to develop abdominal obesity that normotensive individuals.

One study ${ }^{(11)}$ verified in the bivariate analysis that men who self-reported hypertension presented a prevalence ratio 1.44 times higher of overweight and obesity; for women this ratio was 1.72. After applying Poisson regression, self-reported hypertension remained significant for both sexes.

Abdominal circumference is used to classify different degrees of abdominal obesity, as well as cardiovascular risk, and is another indicator used in epidemiological studies, in addition to BMI. This accumulation of fat in the abdominal region is considered a risk factor for other diseases, such as endocrine, metabolic and cardiovascular diseases, even when BMI is within normal parameters $^{(12)}$. Based on this fact, we investigated the association between this variable and the outcome, which was detected in the bivariate and multivariate analyses. The final model showed that abdominal circumference above normal parameters, which characterizes central obesity, increases 32 times the likelihood of a young adult to develop overweight or obesity.

It is important to note that all the variables addressed in this study have some relationship with overweight/obesity. How strong this relationship is, however, depends on specific populations. The purpose of nurses is to identify which predisposing factors are interfering in the outcome through statistical analysis and then use their clinical and critical rationale to direct practices, be these practices to promote health or to prevent diseases or associate morbidities.

The statistical analysis permits proposing some guiding points to support the clinical practice of nurses 
delivering care to overweight or non-overweight young adult students, directing the practice of health education.

These points include considering that obesity involves biological, historical, ecological, economic, cultural, social and political factors, the causes of which are not only individual, but also environmental and social. Nurses should work to reach young adult students who do not usually seek the conventional health service network, and visit social spaces such as schools to promote the establishment of bonds between the health unit and the school, enabling the implementation of a quality multidisciplinary service to prevent diseases and promote health.

It is worth noting that nurses are supposed to provide nursing consultations, monitor anthropometric data and ask for complementary exams to assess those at risk and refer these individuals to specialized professionals when necessary; identify together with the young adult what factors contributed, contribute or will contribute to overweight, from the perspective of diet, social and sportive behavior, and together seek strategies to overcome these factors; to overcome environmental and social factors, nurses and young adults should use the strategies proposed by public health policies and health care insurance/plans concerning the clinical condition; when overweight has already settled in, methods that minimize the risk of associated morbidities should also be used.

It is important to consider that nurses should have the support of other health care workers providing integral and interdisciplinary care to overweight or nonoverweight young adults; all intervenient factors should be addressed by the nurse, considering the strategy to promote the health of young adult students who have not yet become overweight by using educational practices; and finally, nurses should always update their knowledge concerning research addressing the clinical care they provide, in addition to conduct studies to contribute to the implementation of such care.

\section{Conclusion}

After bivariate analysis and adjustment of the multivariate analysis, the following variables remained in the final model: having a partner, overweight during adolescence, diastolic blood pressure indicating hypertension and augmented abdominal circumference.

All the variables tested in this study were subject to be statistically associated with overweight/obesity because they were based on various studies developed on this topic. One has to consider, however, the age interval of this young population addressed in this study. Many of the predictor variables would require longer periods to fully manifest. Other factors may have contributed to a lack of association: e.g. the accuracy of the answers provided by the participants was not take into account.

The conclusion, therefore, is that the analysis of the predictor variables for excess weight in young adult students support nurses in the planning and development of educational practices aimed to prevent this clinica condition, a risk factor for other chronic comorbidities, such as cardiovascular diseases.

\section{References}

1. World Health Organization. World Health Statistics 2012. 2012 [acesso em: 6 out 2014]. Disponível em: http://www.who.int/gho/publications/world_health_ statistics/WHS2012_IndicatorCompendium.pdf?ua $=1$

2. Rodrigues EM, Boog MCF. Problematização como estratégia de educação nutricional com adolescentes obesos. Cad Saúde Pública. 2009;22(5):923-31.

3. Oliveira AFC, Nogueira MS. Obesidade como fator de risco para a hipertensão entre profissionais de enfermagem de uma instituição filantrópica. Rev Esc Enferm USP. 2010;44(2):388-94.

4. Câmara Interministerial de Segurança Alimentar e Nutricional (CAISAN). Plano Intersetorial de Prevenção e Controle da Obesidade: promovendo modos de vida e alimentação adequada e saudável para a população brasileira. 2011. [acesso em: 10 nov 2012]. Disponível em: http://189.28.128.100/nutricao/docs/geral/ apresentacao_plano_obesidade2.pdf

5. Mariz LS, Medeiros CCM, Vieira CENK, Enders BC, Coura AS. Changes in the frequency of food intake among children and teenagers: monitoring in a reference service. Rev. Latino-Am. Enfermagem. 2013;21(4):973-81.

6. Medeiros CCM, Xavier IS, Santos VEFA, Souza MAO, Vasconcelos AS, Alves ERP. Obesidade infantil como fator de risco para a hipertensão arterial: uma revisão integrativa. REME. 2012;16(1):111-9.

7. Souza MCC, Tibúrcio JD, Bicalho MF, Rennó MS, Dutra JS, Campos LG et al. Fatores associados à obesidade e sobrepeso em escolares. Texto Contexto Enferm. 2014;23(3): 712-9.

8. Instituto Brasileiro de Geografia e Estatística (IBGE) Dados do Censo 2010 publicados no Diário Oficia da União. Dados: Maracanaú/Ceará. 2010. [acesso 
em: 18 julho 2010]. Disponível em: http://www. senadorsaonline.com.br/2010/12/censo-2010-confiraos-dados-do-estado.html

9. VI Diretrizes Brasileiras de Hipertensão. Arq Bras Cardiol [internet] 2010. [acesso em: 2 novembro 2014];95(supl1):I-III. Disponível em: http://www. scielo.br/scielo.php?script $=$ sci_arttext\&pid=S0066$782 \times 2010001700001 \& \operatorname{lng}=$ en

10. Costa MAP, Vasconcelos AGG, Fonseca MJM. Prevalência de obesidade, excesso de peso e obesidade abdominal e associação com prática de atividade física em uma universidade federal. Rev Bras Epidemiol. 2014;17(2):421-36.

11. Lino MZR, Muniz PT, Siqueira KS. Prevalência e fatores associados ao excesso de peso em adultos: inquérito populacional em Rio Branco, Acre, Brasil, 2007-2008. Cad Saúde Pública. 2011;27(4):797-810.

12. Veloso HJF, Silva AAM. Prevalência e fatores associados à obesidade abdominal e ao excesso de peso em adultos maranhenses. Rev Bras Epidemiol. 2010;13(3):400-12.

13. Gordon-Larsen $P$, The NS, Adair LS. Longitudinal trends in obesity in the United States from adolescence to the third decade of life. Obesity (Silver Spring). 2010; 18:1801-1804.

14. Yannakoulia M, Panagiotakos D, Pitsavos C, Lentzas Y, Chrysohoou C, Skoumas I et al. Five-year incidence of obesity and its determinants: the ATTICA Study. Public Health Nutrition. 2009;12(1):36-43.

15. Alves JGB, Siqueira PP, Figueiroa JN. Excesso de peso e inatividade física em crianças moradoras de favelas na região metropolitana do Recife, PE. J Pediatr. 2009;85(1):67-71.

16. Gopinath B, Baur AL, Burlutsky G, Mitchell P. Socioeconomic, familial and perinatal factors associated with obesity in Sydney schoolchildren. J Pediatrics Child Health. 2012;48(1):44-51.

17. Ramos-Arellano LE, Benito-Damián F, SalgadoGoytia L, Muñoz-Valle JF, Guzmán-Guzmán IP, VencesVelázquez $A$, et al. Body fat distribution and its association with hypertension in a sample of Mexican children. J Investig Med. 2011;59(7):1116-20.

18. Cristóvão MF, Sato APS, Fujimori E. Excesso de peso e obesidade abdominal em mulheres atendidas em Unidade da Estratégia Saúde da Família. Rev Esc Enferm USP 2011;45(esp2):1667-72. 